\title{
An in situ video camera for plankton studies: design and preliminary observations
}

\author{
Peter Tiselius* \\ Kristineberg Marine Research Station, S-450 34 Fiskebäckskil, Sweden
}

\begin{abstract}
A design for an in situ video camera for plankton observations is presented. A light weight aluninium rig supports a video camera with an opposing stroboscope which produces dark field images of plankton $>0.3 \mathrm{~mm}$. In the present configuration the camera can be used down to $100 \mathrm{~m}$ and provides video images of 10 to $40 \times$ magnification when viewed on a 14 " (ca $35 \mathrm{~cm}$ ) monitor. Video recordings from the field show moderate aggregations of small copepods to the subsurface fluorescence maximum and at times indications of horizontal patchiness. The large copepod Calanus finmarchicus was found to aggregate $5 \mathrm{~m}$ below the fluorescence maximum at night. In comparisons with a traditional WP-2 plankton net, the video camera provided similar length frequency distributions while abundance estimates from video recordings were 10 to $20 \%$ higher than net estimates. It is concluded that the presented video camera offers excellent observations of the pelagic environment at an affordable cost.
\end{abstract}

KEY WORDS: Fine-scale distribution - Copepods - Gelatinous plankton Marine snow

\section{INTRODUCTION}

In the study of structure and function of the pelagic ecosystem, focus has been drawn towards successively smaller scales and currently the interaction between single individuals is under discussion although such interaction has not yet been observed in situ (e.g. Haury \& Yamazaki 1995, Leising \& Yen 1997). To explain critical features such as food uptake, predator avoidance and mate finding, an individual approach is necessary. In the laboratory these behaviours have been studied (e.g. Uchima \& Hirano 1988, Tiselius 1992, Yen \& Fields 1992), but the realism of experimental conditions is still not known. In situ observations of copepods are rare and only a few accounts of behaviour exist (e.g. Bainbridge 1952, Ueda et al. 1983, Buskey et al. 1996).

A promising technique for in situ studies of plankton is the use of video cameras, either fixed in one position to study shallow water species (Buskey et al. 1996) or suspended to observe occurrences of pelagic species

•E-mail: p.tiselius@kmf.gu.se
(Davis et al. 1992a). The video plankton recorder (VPR; Davis 1992a) has produced interesting results on horizontal patchiness of various plankton (Davis et al. $1992 b)$ and is a feasible way to sample both in the vertical and horizontal plane. The VPR was designed for open ocean use with low abundances of copepods and a 'real-time' image analysis system was found necessary to handle the large number of empty video frames collected during a deployment. In coastal waters, however, copepods are 1 to 2 orders of magnitude more abundant and a manual analysis of the video recordings is possible.

The advantage of a video system over electronic or optical particle counters is that the environment can be observed. An in situ silhouette camera has been used to quantify Gulf Stream plankton (Ortner et al. 1981), but it required a concentrating net to collect enough animals on each photograph. While particle counters have the advantage that they process a large number of particles which can give reliable estimates of even separate stages of copepods (Herman \& Mitchell 1981. Herman 1988), they provide little information about the environment as experienced by the plankton. The importance of small-scale turbulence (Kiørboe \& Saiz 
1995) and possible coherent structures in the water (Yamazaki 1993) need to be verified by field observations for which video is the only choice. The pelagic environment also contains many fragile organisms or aggregations of potential food. Gelatinous plankton are important predators and may reveal their true predatory capacity only through video observations, which do not disturb their tentacles. The true appearance of marine snow is only revealed by optical sampling (e.g. Riebesell 1991), which allows quantification without destroying the aggregates.

In this paper I describe an in situ video camera built to study plankton in coastal waters. The general design is based on the VPR by Davis et al. (1992a), but with substantial simplifications to keep the cost down and still retain the optical properties. The purpose of the camera is not only to quantify copepod abundance but also to give an in situ view of the pelagic environment as experienced by a copepod. A comparison with abundances obtained with net tows is made and vertical and horizontal profiles from 3 sampling occasions are presented.

\section{MATERIAL AND METHODS}

Description of the video camera. The camera rig is made of $40 \times 40 \mathrm{~mm}$ aluminium profiles and consists of 3 underwater pressure cases containing the camera, the stroboscope and the electronics (Figs. 1 \& 2). The camera is a high sensitivity black-and-white video camera (OSCAR OS-458, $795 \times 595$ pixels $1 / 2$ " CCD chip) fitted with a Vivitar $100 \mathrm{~mm} f 2.81 \times 1$ macro telephoto lens. The camera case is made from a $76 \mathrm{~mm}$ inner diameter, $6 \mathrm{~mm}$ wall PVC pipe with a $25 \mathrm{~mm}$ thick Plexiglas lid in front and a $30 \mathrm{~mm}$ thick PVC lid with cable connections in the back. Opposite the cam-

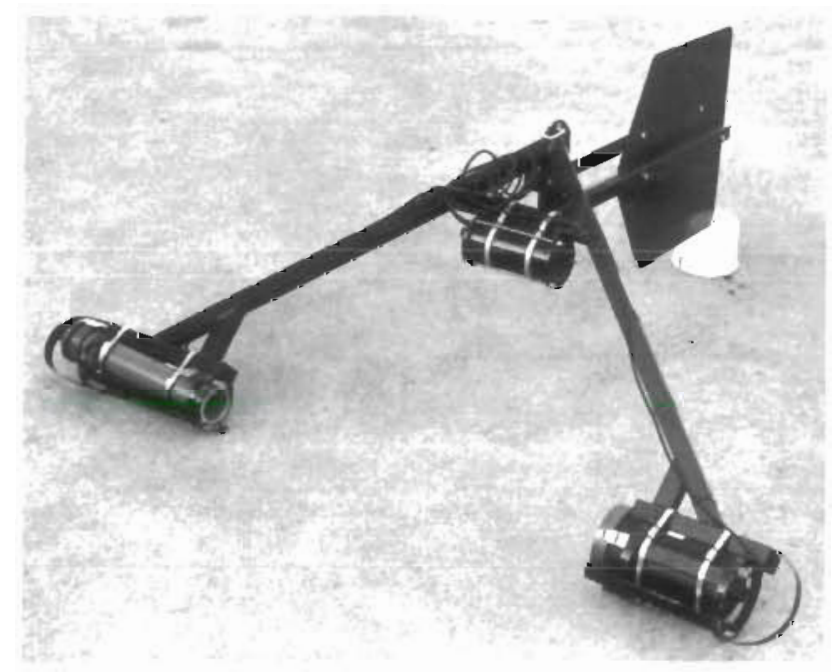

Fig. 1. The in situ video camera for use in plankton studies
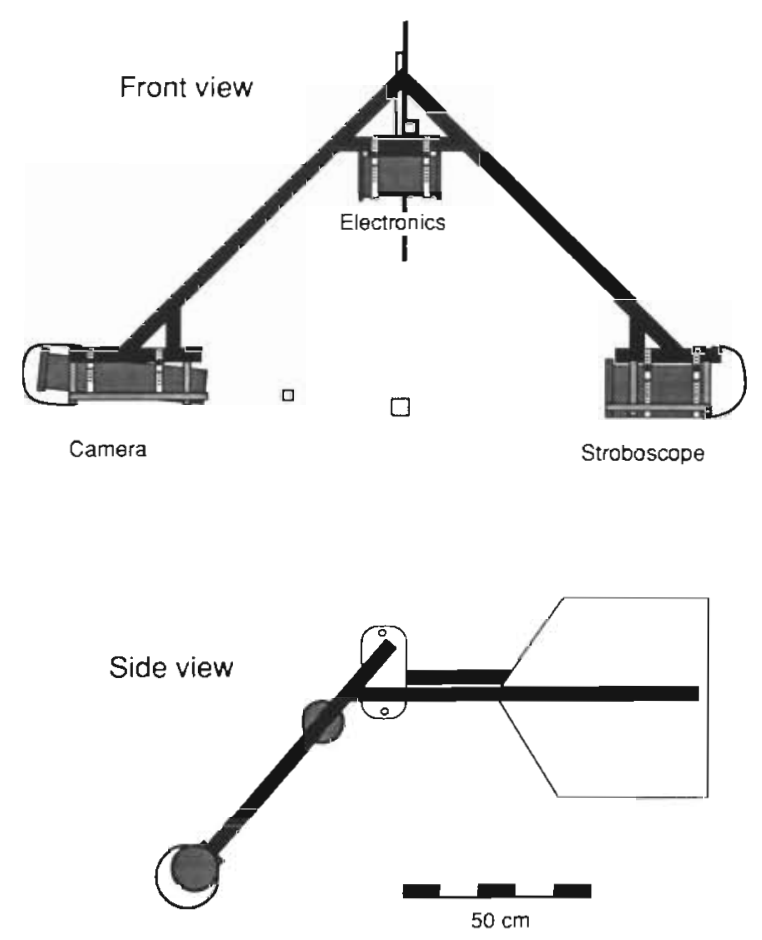

Fiy. 2. Scilemalic drawing of the in situ video camera. Observation volumes at high and low magnifications are indicated as squares between the camera and the stroboscope. Note the oblique angle of the camera allowing dark field illumination. The $22 \mathrm{~V}$ DC power cable and the video coaxial cable both connect to the right hand side of the electronic housing

era, $1 \mathrm{~m}$ away, is a $7 \mathrm{~W}$ stroboscope (Cole Parmer $87000)$ with a flash duration of $20 \mu$ s housed in a similar pipe. The stroboscope is manually adjusted to send either $1(50 \mathrm{~Hz})$ or $2(100 \mathrm{~Hz})$ flashes for each video field. The camera case is mounted at an oblique angle to the stroboscope light beam and this arrangement provides dark-field illumination. The electronics are housed in an aluminium pipe mounted at the intersection of the 2 arms. Power is supplied at $22 \mathrm{~V} \mathrm{DC}$ through a $3 \times 0.75 \mathrm{~mm}^{2}$ cable and adjusted to 6 and $12 \mathrm{~V}$ by the use of voltage regulators mounted on the aluminium lids (for cooling) of the electronic housing. The approximate cost of the complete rig, camera, stroboscope and electronics, is US $\$ 4000$.

The rig is almost neutrally buoyant but kept horizontally aligned at the sampling depth by suspending a $20 \mathrm{~kg}$ weight below. Behind the filming area is a vane $(60 \times 60 \mathrm{~cm})$ to align the camera perpendicular to the flow. Once aligned with the flow, no hydrodynamic disturbance from the rig can be observed in the images. Video signals are transmitted unamplified through a coaxial cable to the surface, where they are passed through a time code generator (Panasonic WJ-810), recorded on a Panasonic FS-200 S-VHS VCR and displayed on a Panasonic BT-H1450Y 14" (ca $35 \mathrm{~cm}$ ) monitor. 
Analyses of the video recordings. To estimate the volume sampled by the camera, knowledge of the current velocity and depth of field are required. By setting the stroboscope to $100 \mathrm{~Hz}, 2$ images in each field (S-VHS; 50 fields $\mathrm{s}^{-1}$ ) are recorded. The current velocity can then be estimated as the distance between 2 images of each object on a single video field [= distance traversed $\left(0.02 \mathrm{~s}^{-1}\right]$. Non-moving objects were preferably used, but even non-escaping copepods could be used since their speed is slow compared to the water flow passing by the camera. Calibration of the depth of field followed the method of Davis et al. (1992a), i.e. a copepod glued to a hair was mounted on a micro manipulator and moved back and forth through the depth of field. The calibration was done underwater with the same stroboscope illumination as during regular sampling. By repeating this 20 times, the depth of field was determined for different magnifications with a coefficient of variation of 8 to $12 \%$.

The point of focus between the camera and the stroboscope depends on desired magnification. In studies of marine snow (Tiselius \& Kuylenstierna 1996, Kiørboe et al. 1998, Tiselius \& Kiørboe 1998), we focused on a volume positioned exactly between the camera and stroboscope which gave a volume of $23.6 \mathrm{ml}$ for each video field. In the present study, a higher magnification was used to study copepod distributions and the focal point was set at $12 \mathrm{~cm}$ from the front of the camera housing. At this magnification the width and height of the observed volume were 8.1 and $6.1 \mathrm{~mm}$, respectively, producing a sampled volume of $0.42 \mathrm{ml}$ for each video field. With the high magnification used, copepodites $>0.3 \mathrm{~mm}$ could be recognised, and adult stages determined to species. Cephalothorax lengths were measured directly on the monitor screen with a ruler.

Depending on copepod abundance, the video tapes were analysed either continuously as an unbroken stretch of water or by analysing single, randomly selected fields. The first method requires the velocity calculations described above and records true horizontal distance between organisms at the smallest scale. The second method samples a series of nonoverlapping volumes randomly at the same depth and patchiness on a larger scale may be detected. The motion of the camera rig is produced by the ship's passive drifting or currents and typically ranges from 10 to $50 \mathrm{~cm} \mathrm{~s}^{-1}$.

Sampling in the field. Video recordings were done on 3 occasions: 30 July and 20 September 1993 at Gåsö, Sweden (58 $\left.14.6^{\prime} N, 11^{\circ} 25.6^{\prime} \mathrm{E}\right)$ and 25 to 26 May 1994 in the central part of Skagerrak $\left(58^{\circ} 10.0^{\prime} \mathrm{N}\right.$, $9^{\circ} 26.4^{\prime}$ E). Profiles for salinity and temperature were taken with a Neil Brown Mk III conductivity' temperature/depth profiler (CTD). Vertical net tows with a $200 \mu \mathrm{m}$ WP-2 net were performed to compare abundances with the video recordings. Copepods were preserved in $4 \%$ formalin and enumerated under a dissecting microscope after subsampling $1 / 10$ to $1 / 100$ of the sample (Kott 1953). Cephalothorax lengths were measured with an eye-piece micrometer.

Video recordings were made by filming continuously for 3 to $5 \mathrm{~min}$ at each depth. Depth was recorded from a depth sensor on the in situ fluorometer (see below) or by an attached mini-CTD (ADM 120). In the case of vertical profiles, all copepods were counted at a selected depth, then 4 depths were averaged and the variance estimated. To provide a measure of horizontal variability, one depth stratum was filmed continuously for 10 min on some sampling occasions. Horizontal transects were divided into $5 \mathrm{~m}$ intervals and the mean and variance of 4 intervals estimated. Comparisons of abundance between depths or between segments of the transects were done with ANOVA and StudentNewman-Keuls (SNK) post hoc tests (Sokal \& Rohlf 1981).

Potential co-occurrence of copepods and in situ fluorescence was investigated by suspending an in situ fluorometer ( $Q$-instruments) under the rig so that water passing the viewing volume could also be analysed for fluorescence. The signals from the fluorometer were recorded simultaneously with the filming and used for correlations between fluorescence and copepod abundance. Significance was tested by t-tests of correlation coefficients (Sokal \& Rohlf 1981).

\section{RESULTS AND DISCUSSION}

\section{Field observations}

The video camera provides up to $40 \times$ magnification if viewed on a 14 " monitor and this gives excellent resolution of even small plankton. The highest magnification was used for the profiles in the present study and it was necessary to analyse the recordings frame by frame to quantify copepods. The environment, however, is better viewed at lower magnification $(10 \times)$ since this gives an impression of the living space for the plankton. Larger diatom chains show up well and predators on copepods such as chaetognaths and a variety of medusae can be observed. At the lower magnification the camera can be used in real time to give a picture of the general stratification of the biota. Copepods are conspicuous and will be noted even if they pass by quickly. Used in this way, the camera has proven highly informative when deciding on which depth to sample in the field (Tiselius \& Kiørboe 1998). The main reason for constructing the camera, however, was to investigate vertical and horizontal distributions 
of copepods related to indices of their food environment. Three occasions are presented in this paper to illustrate the type of information that may be gathered with the camera.

The first 2 samplings were done at the coastal station Gåsö, where small copepods and copepodites dominate the plankton. On the first occasion, 30 July, the weather was calm and a strong subsurface peak in fluorescence was observed (Fig. 3). Wind-induced vertical mixing was estimated to be very low. There was a significant difference in copepod abundance at the depths sampled (1-factor ANOVA, df $=5,15 ; F=4.60$, $p<0.01$ ). Copepod abundance generally declined with depth and copepods were significantly more abundant (SNK post hoc test, $p<0.05$ ) at the depth of the maximum fluorescence. Accordingly the fluorescence and abundance were also significantly correlated $(t=2.646$, $\mathrm{df}=19,0.01<\mathrm{p}<0.02$ ). To estimate horizontal variability, continuous filiming was done for $10 \hat{0}$ nin in the fluorescence maximum at $11 \mathrm{~m}$. Variability was pronounced along the transect but there was no trend in abundance over the distance.

On the other occasion, 20 September, the woather was windy and the upper $9 \mathrm{~m}$ well mixed (Fig. 4). No fluorescence maximum was observed and the cope-

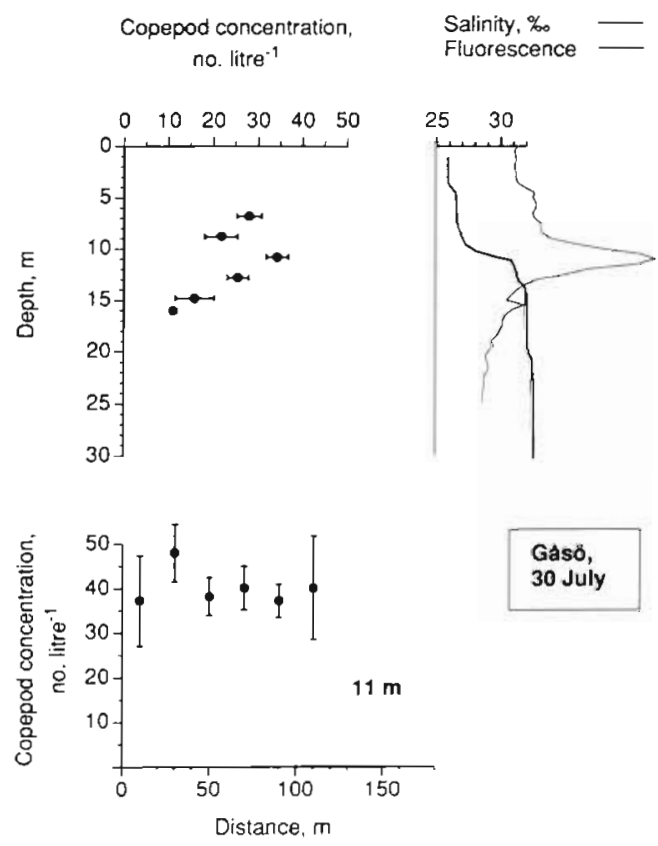

Fig. 3. Abundance of copepods determined with the video camera at station Gásö on 30 July 1993. For the vertical profile (upper left panel) each data point is the average of four $0.5 \mathrm{~m}$ depth intervals, each filmed for $3 \mathrm{~min}$. In the honzontal transect (lower panel) a continuous stretch of water at $11 \mathrm{~m}$ was filmed and each data point is the average of 4 consecutive $5 \mathrm{~m}$ intervals. Error bars $=\mathrm{SE}(\mathrm{n}=4)$. For companison the salinity and relative fluorescence (relative units) profiles are shown pods were evenly distributed in the mixed layer with abundances between 30 and 40 copepods $1^{-1}$. Abundances varied considerably, but if samples are grouped in 2 groups, copepods in the mixed layer were significantly more abundant than in the deeper water ( 1 -factor ANOVA, df $=1,22, F=12.9, p=0.0016$ ). The correlation between fluorescence and copepod abundance was significant $(t=2.972, \mathrm{df}=20,0.001<\mathrm{p}<$ 0.01 ), but this was probably due to the general depth dependence of both fluorescence and copepods. The horizontal transect showed a trend of declining abundances over a $100 \mathrm{~m}$ distance. After $130 \mathrm{~m}$ abundances were significantly lower ( 1 -factor ANOVA, df $=7,23$; $F=4.71, p=0.0021$ ), which is an indication of relatively sharp horizontal gradients in copepod abundance.

The 2 profiles dominated by small copepods showed that their distributions were related to the mixing conditions. With little wind mixing, the strong fluorescence maximum caused aggregation of evcn wcak swimmers like small copepods. With stronger winds, copepods as well as algae were mixed in the entire surface layer.

My final example is from the central Skagerrak, where 5 vertical profiles of the large copepod Calanus finmarchicus were recorded at a $24 \mathrm{~h}$ fixed station. Abundances were lower than at the coastal station but at 21:40 h a clear vertical migration resulted in abun-
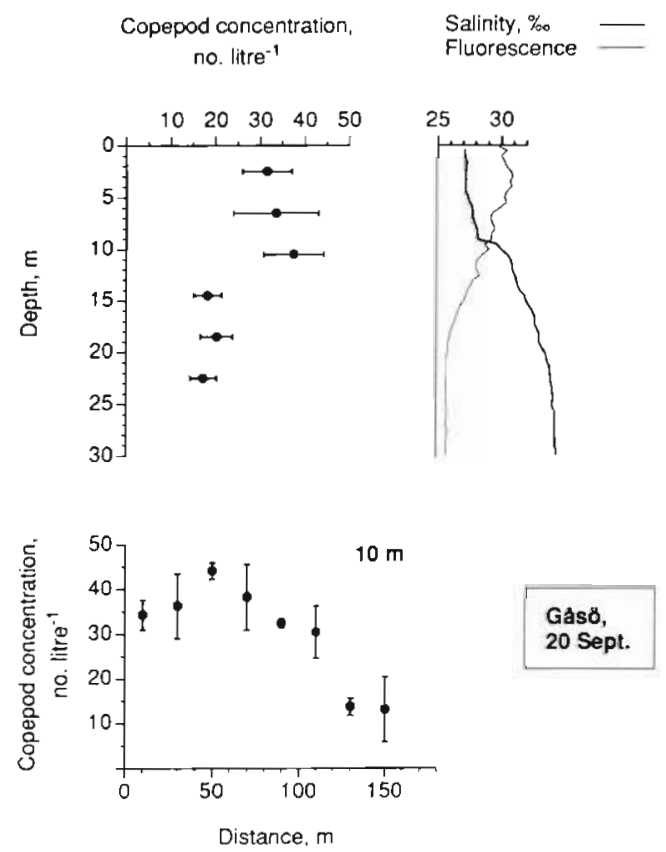

Fig. 4. Abundance of copepods determined with the video camera at station Gåsö on 20 September 1993. For the vertical profile (upper left panel) each data point is the average of four $1 \mathrm{~m}$ depth intervals, each filmed for $3 \mathrm{~min}$. The horizontal transect at $10 \mathrm{~m}$ was analysed as in Fig. 3. Error bars $=\mathrm{SE}$ $(n=4)$. For comparison the salinity and relative fluorescence (relative units) profiles are shown 

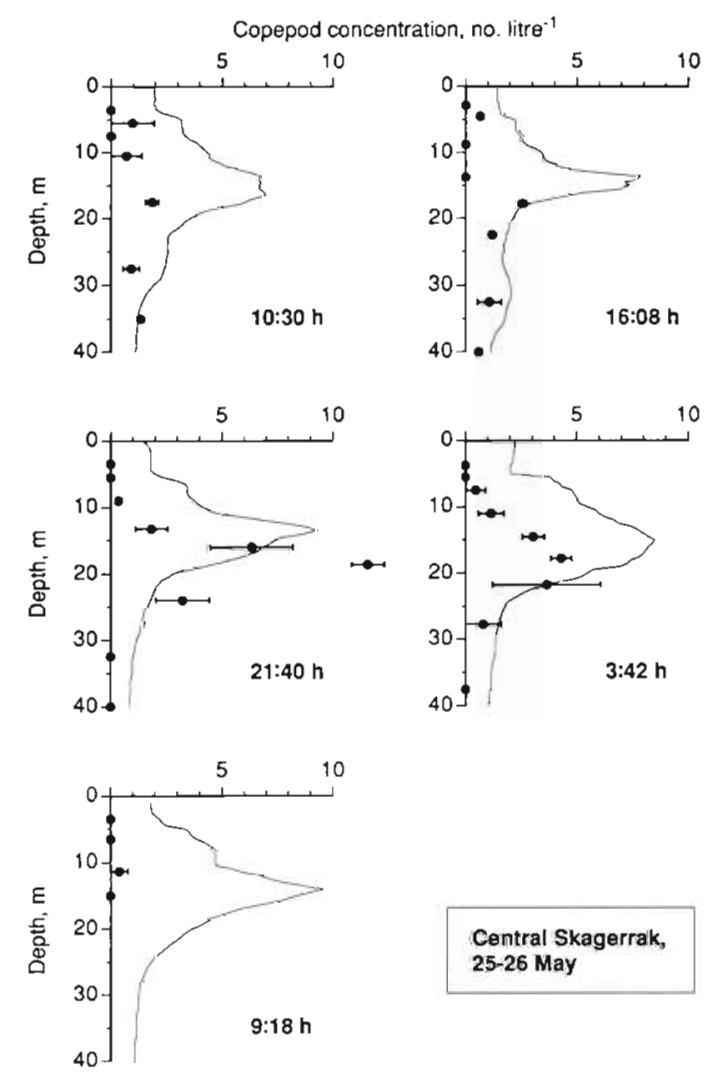

Central Skagerrak, 25-26 May

Fig. 5. Vertical profiles of Calanus finmarchicus abundance at a $24 \mathrm{~h}$ fixed station in central Skagerrak on 25 to 26 May 1994. Sampling times and relative fluorescence (thin line) are included in the figure. Each data point represents the average of 2 depth intervals, and in contrast to Figs. $3 \& 4$, the depth intervals are not equal (range 1 to $5 \mathrm{~m}$ ). Three minutes filming at each depth. Error bars $=\mathrm{SE}(\mathrm{n}=2)$

dances up to 12 ind. $\mathrm{I}^{-1}$ at $17 \mathrm{~m}$ depth (Fig. 5). Such high concentrations of $C$. finmarchicus may exert a very strong grazing pressure within a limited depth interval. The camera allowed the precise location of this depth and an estimate of the local copepod abundance. Interestingly, maximum abundance was found consistently below the fluorescence peak and the upwards migrating copepods stayed below $15 \mathrm{~m}$. In contrast to sampling with a plankton net, the video camera reveals the consistent separation between the fluorescence peak and copepod abundance peak. With more information on the composition of algae at the fluorescence peak and the potential copepod predator abundance in the surface water, the reason for this migration behaviour could possibly be explained.

\section{Comparison with plankton nets}

Quantifying copepods with the video yields 10 to $25 \%$ higher abundances than traditional net tows

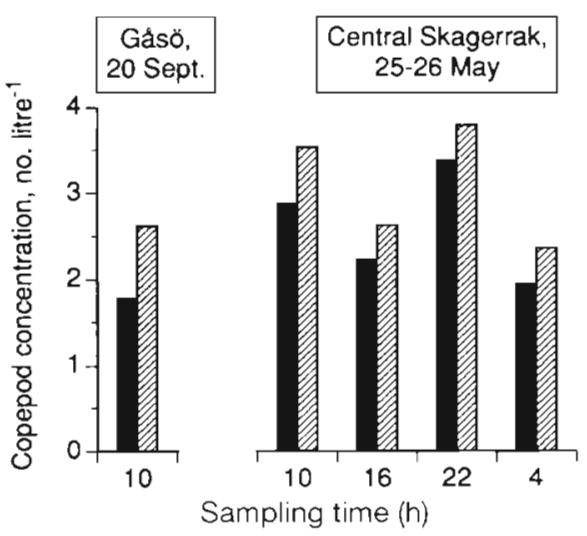

Fig. 6. Average integrated copepod abundance determined with the video camera (国) and vertical tows with a $200 \mu \mathrm{m}$ WP-2 net ( $\square$ ). The comparison is restricted to copepods $\geq 0.6 \mathrm{~mm}$ since smaller specimens may escape through the meshes of the net. To make the video recorded profiles comparable to integrated tows, recordings at discrete $5 \mathrm{~m}$ intervals were used

through the same water column (Fig. 6). The comparison is only valid for late copepodite stages or adults since most juveniles are lost through the $200 \mu \mathrm{m}$ meshes of the WP-2 net (Hernroth 1987). Even so, a strict comparison between discrete sampling at fixed depths with an integrated net tow is not possible due to vertical patchiness. As copepods occurred in layers (Fig. 4), filming at a depth of high abundance makes the average integrated abundance calculated for that water column disproportionally high. Other reasons for the discrepancy between camera and net determined abundances include escape responses from the net and potential attraction to the stroboscope light. These factors were not investigated here. In general, however, the camera and nets give similar abundance estimates, but in cases of strong vertical zonation of plankton the camera collects ecologically more relevant abundance data, given that the layers of high abundance can be observed.

With the camera it is possible to collect a size frequency distribution that is not biased by the retention of plankton nets. The length distributions from video analyses may be skewed towards smaller sizes since copepods may not be aligned perpendicular to the camera. Despite this, analyses on preserved samples and video recordings compare favourably for copepods larger than $0.6 \mathrm{~mm}$ (Fig. 7). Although the video analysis merges the peaks of Calanus finmarchicus copepodite stage 4 and 5 into one $(1.8$ to $2.8 \mathrm{~mm}$; Fig 7 . lower panel), there is little difference in the length estimates of larger individuals. This can be expected for $C$. finmarchicus since it has a predominantly vertical posture perpendicular to the camera. For sizes below $0.8 \mathrm{~mm}$ the differences become important; the 


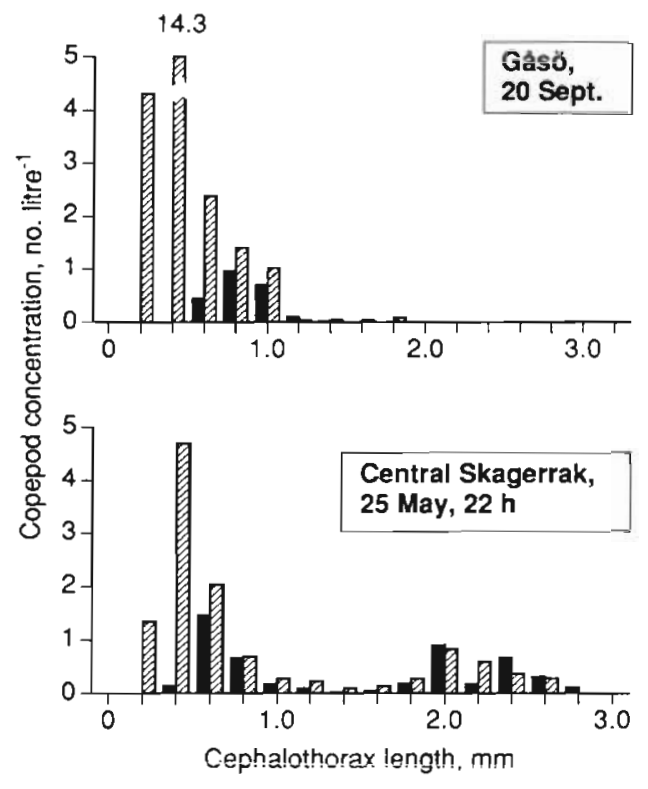

Fig. 7. Size frequency distributions obtained by video recordings (囷) and vertical net tows with a $200 \mu \mathrm{m}$ WP-2 net ( $\square$ ). As in Fig. 6, only data from video recordings at discrete $5 \mathrm{~m}$ intervals were used

video shows peak abundances in the $0.4 \mathrm{~mm}$ size class and even high numbers in the smallest category (Fig. 7, upper panel). The smallest calanoid copepodites are 200 to $300 \mu \mathrm{m}$ (Berggreen et al. 1988), indicating that the camera probably records the full range of copepodite stages. If smaller copepods should tend to swim more horizontally than $C$. finmarchicus, the size frequencies may be biased towards smaller sizes. This is not the impression from the video recordings, however.

A bias in the length frequency distribution may arise due to uneven lighting of the observation volume. Small, brightly lit objects will appear bigger than large, poorly lit objects. With the present optical set up, however, the viewing area is small and the viewing angle narrow $\left(\approx 9^{\circ}\right)$, which minimises this problem.

\section{CONCLUSIONS}

The video camera arrangement presented provides unique opportunities to observe plankton in a relatively undisturbed habitat. At high magnification it allows detailed investigations of fine-scale vertical and horizontal distributions of copepods and other plankton larger than $0.3 \mathrm{~mm}$. The resolution is sufficient to allow species identification for adult copepods. At lower magnification it allows valuable information to be gathered on the living space of plankton. The strong vertical zonation of animals and plants becomes evident when viewed through the video camera and a sampling strategy can be designed accordingly. Fragile organisms such as medusae and gelatinous plankton have to be observed undisturbed to fully appreciate their impact as predators and the video camera allows this. Finally, video or other photographic methods are necessary to show size, shape and abundance of marine snow. While quantitative analysis from video films is tedious, use of video as an in situ observation tool is superior to net collections. Knowledge gained from in situ observations is crucial for any attempt to understand the functioning of the pelagic ecosystem and can be used to design a sampling series or a realistic set of experiments. The present construction provides excellent information at an affordable cost.

Acknowledgements. This work was supported by the Swedish Natural Science Research Council, grant no. B-AA/BU 09889. I am grateful for comments from Enric Saiz on the construction of the camera and for technical assistance from Christer Gren.

\section{LITERATURE CITED}

Bainbridge $R$ (1952) Underwater observations on the swimming of marine zooplankton. J Mar Biol Assoc UK 31 $107-112$

Berggreen U, Hansen B, Kiørboe T (1988) Food size spectra, ingestion and growth of the copepod Acartia tonsa during development: implications for the determination of copepod production. Mar Biol 99:341-352

Buskey EJ, Peterson JO, Ambler JW (1996) The swarming behavior of the copepod Dioithona oculata: in situ and laboratory studies. Limnol Oceanogr 41:513-521

Davis CS, Gallager SM, Berman MS, Haury LR, Strickler JR (1992a) The Video Plankton Recorder (VPR): design and initial results. Arch Hydrobiol Beih Ergebn Limnol 36: $67-81$

Davis CS, Gallager SM, Solow AR (1992b) Microaggregations of oceanic plankton observed by towed video microscopy. Science 257:230-232

Haury LR, Yamazaki H (1995) The dichotomy of scales in the perception and aggregation behavior of zooplankton. J Plankton Res 17:191-197

Herman AW (1988) Simultaneous measurement of zooplankton and light attenuance with a new optical plankton counter. Cont Shelf Res 8:205-221

Herman AW, Mitchell MR (1981) Counting and identifying copepod species with an in situ electronic zooplankton counter. Deep Sea Res 28A:739-755

Hernroth L (1987) Sampling and filtration efficiency of two commonly used plankton nets. A comparative study of the Nansen net and the Unesco WP 2 net. J Plankton Res $9(4): 719-728$

Kiørboe T, Saiz E (1995) Planktivorous feecing in calm and turbulent environments, with emphasis on copepods. Mar Ecol Prog Ser 122:135-14.5

Kiørboe T, Tiselius P, Mitchell-Innes BA, Hansen JLS, Visser AW, Mari X (1998) Intensive aggregate formation but low vertical flux during an upwelling induced diatom bloom. Limnol Oceanogr (in press)

Kott P (1953) Modified whirling apparatus for the subsampling of plankton. Aust J Mar Freshwat Res 4:387-393

Leising AW, Yen J (1997) Spacing mechanısms within Iight- 
induced copepod swarms. Mar Ecol Prog Ser 155:127-135

Ortner PB, Hill LC, Edgerton HE (1981) In-situ silhouette photography of Gulf Stream zooplankton. Deep Sea Res 28A: $1569-1576$

Riebesell U (1991) Particle aggregation during a diatom bloom. II. Biological aspects. Mar Ecol Prog Ser 69: $281-291$

Sokal RR, Rohlf FJ (1981) Brometry. WH Freeman and Co, San Francisco

Tiselius P (1992) Behavior of Acartia tonsa in patchy food environments. Limnol Oceanogr 37:1640-1651

Tiselıus P, Kiørboe T (1998) Colonization of diatom aggregates by the dinoflagellate Noctiluca scintillans. Limnol Oceanogr (in press)

Tiselius P, Kuylenstiema M (1996) Growth and decline of a

Editorial responsibility: Otto Kinne (Editor),

Oldendorf/Luhe, Germany diatom spring bloom: phytoplankton species composition, formation of marine snow and the role of heterotrophic dinoflagellates. J Plankton Res 18:133-155

Uchima M, Hirano R (1988) Swimming behavior of the marine copepod Oithona davisae: internal control and search for environment. Mar Biol 99:47-56

Ueda H, Kuwahara A, Tanaka M, Azeta M (1983) Underwater observations on copepod swarms in temperate and subtropical waters. Mar Ecol Prog Ser 11:165-171

Yamazaki $H$ (1993) Lagrangian study of planktonic organisms: perspectives. Bull Mar Sci 53:265-278

Yen J, Fields DM (1992) Escape responses of Acartia hudsonica (Copepoda) nauplii from the flow field of Temora longicornis (Copepoda). Arch Hydrobiol Beih Ergebn Limnol 36:123-134

Submitted: December 1, 1997; Accepted: February 26, 1998 Proofs received from author(s): March 26, 1998 